\title{
A Nondestructive Instrumented Wheelset System for Contact Forces Measurements
}

\author{
Jianbin Wang, Dadi Li, Sheng Qu, Dafu Zhang \\ Traction Power State Key Laboratory, Southwest Jiaotong University, Chengdu, China \\ Email: jianbin.wang@swjtu.edu.cn
}

How to cite this paper: Wang, J.B., Li, D.D., Qu, S. and Zhang, D.F. (2021) A Nondestructive Instrumented Wheelset System for Contact Forces Measurements. Engineering, 13, 361-371.

https://doi.org/10.4236/eng.2021.137026

Received: May 28, 2021

Accepted: July 2, 2021

Published: July 5, 2021

Copyright $\odot 2021$ by author(s) and Scientific Research Publishing Inc. This work is licensed under the Creative Commons Attribution International License (CC BY 4.0).

http://creativecommons.org/licenses/by/4.0/

(c) (i) Open Access

\begin{abstract}
A nondestructive continuous instrumented wheelset design is proposed based on strain gauges placing inside of the wheel web and wireless telemetry system. The signal feature analysis including frequency contents and high order harmonic ripples is also carried out. The strain gradient decoupling method for vertical and lateral force identification is proposed based on the strain distributions under respective loads. The method implements minimum crosstalk effects and insensitive to the varying contact points. The KMT telemetry system is adopted for wireless inductive powering and signal transferring. The drilling holes on the wheel and axles are avoidable to ensure the integrity and long-term using of the wheelset. Bridging and demodulating schemes for lateral and vertical force are designed respectively as they have dramatic differences at the dynamic signal features. High order harmonic ripple analysis and error estimation are gotten by independent waveforms. Based on the data form calibration test rig, it is indicated that the high order ripple amplitudes are below $10 \%$ of the demodulation amplitudes and fulfill designed requirements.
\end{abstract}

\section{Keywords}

Nondestructive Instrumented Wheelset, Signal Decoupling, Signal Demodulating, Wireless Telemetry

\section{Introduction}

Wheel rail contact forces measurements play a critical role in the vehicle acceptance tests for derailment safety evaluations [1]. This technology is also used in academic research tests such as wheel polygonised wear, rail corrugation, vibration transmission between the vehicles and infrastructures. The most popular approach is an indirect method by measuring elastic deformations of the wheelsets by strain gauges [2]. When the wheel runs over the rail, the periodic strains 
occurring on the wheel web and the axle could be acquired through Wheatstone bridge circuit. The double bridge signals in rotating coordinate which have 90 -degrees phase delays can be demodulated with rotating angles to obtain continuous contact forces in global coordinate system. That is the basic principle of the instrumented wheelset, and it is required high SNR (signal noise ratio) bridge outputs as well as low bridge coupling effects under multiple direction contact forces. E. Gomez et al. [3] introduced some general approaches for instrumented wheelset and concentrated on the high order error controlling method through strain gauge position adjusting. Gullers P. et al. [4] introduced instrumented wheelset that could measure high frequency forces up to $2000 \mathrm{~Hz}$ and adopt dynamic modification factor to eliminate the resonance effects of the wheel web. Furthermore, Hiromichi Kanehara et al. [5] studied wheel rail contact points detection method based on bending stress distribution.

As shown in Figure 1, the holes drilled on the wheel web are the most suitable positions to get the highest sensitivity to the vertical loads and the lowest cross sensitivity to the lateral loads. The strain gauges on the double sides of wheel web closed to the hub are of the highest sensitivity to the lateral loads and the lowest coupling effects to the vertical loads as well. In short, this scheme is the benchmark for all other implementation methods.

Due to the wiring holes on the axle and auxiliary holes on the web, the structural integrity of the wheelset is damaged, and it is only used for acceptance tests or short-term tests for running safety. Nowadays, there is a strong need for a non-destructive instrumented wheelset in long-term tracking tests along with the wear process of the wheels. Placing the strain gauges on the inside wheel web and together with wireless signal transferring system is a feasible solution for the nondestructive instrumented wheelset. This article introduced the implementation principle of the method. The positioning method of the strain gauges based on strain gradients, and the waveform rectifying method for the vertical force were highlighted.

\section{Principle of the Nondestructive Instrumented Wheelset}

Expect for traction and braking states, the lateral and vertical contact forces are of more meanings to the vehicle running safety evaluations such as derailment factors and overturn ratios. This article only concentrated on the lateral and vertical force identifications through elastic deformations of the inside wheel web. It is found that wheel web has uneven deformations under the vertical and lateral loads through FEA. The critical requirement of positioning strain gauges is to get the lowest cross sensitivity to the external loads. It is implemented by algebraic operations of the individual strain gauge through bridge assembling according to the strain gradient features, respectively.

\subsection{Strain Gauges Positioning Method Based on Strain Gradients}

Wheel web stress distributions under vertical and lateral loads were calculated 
individually to get strain gradient features along the radial direction, as shown in Figure 2. Vertical load of varying contact positions is considered as its great influence on the bending stress distributions.
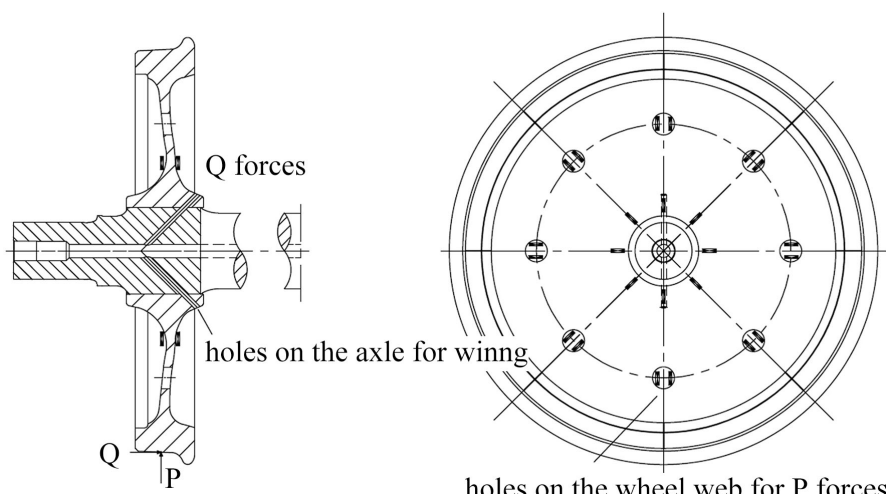

holes on the wheel web for P forces

Figure 1. Conventional instrumented wheelset with drilled holes.

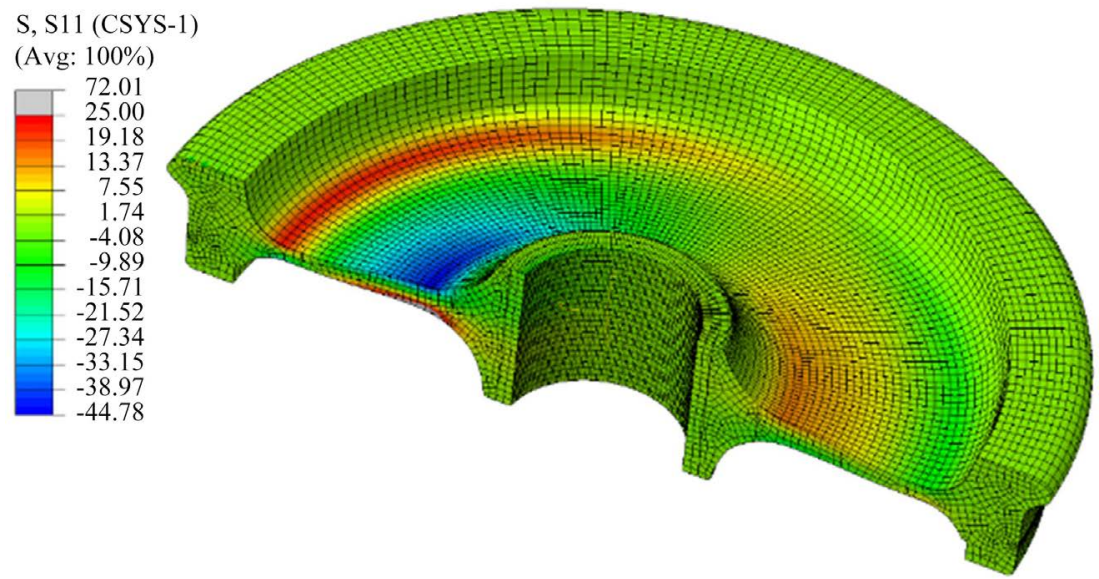

(a)

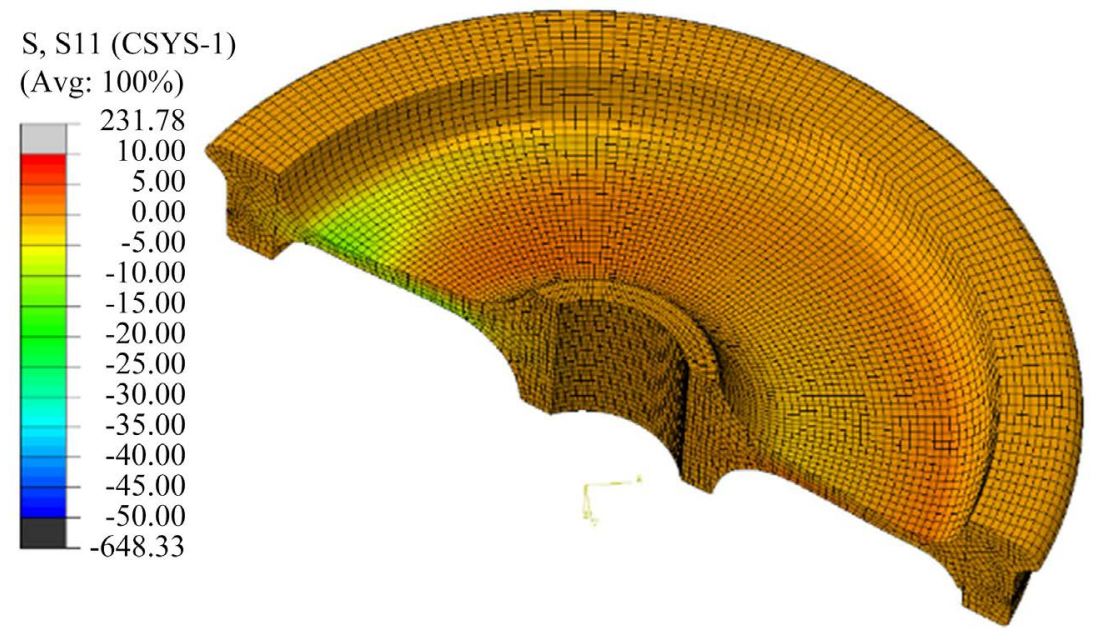

(b)

Figure 2. Stress distributions in radial direction. (a) Lateral loading; (b) Vertical loading. 
The most sensitive zones on the wheel web are CA1, TA1, and CA2 respective to the lateral $(\mathrm{Q})$ and vertical $(\mathrm{P})$ forces, as shown in Figure 3. The stress gradient of TA1 is determined mainly by the lateral force, and it is used for the Q identification. The stress gradient of CA1 is more complicated as the influence zones of the $\mathrm{Q}$ and $\mathrm{P}$ forces are overlapping. Generally, the strains of CA1 are induced by the vertical force, additional bending moment as the misaligned contact position, and bending moment by lateral force. The area CA2 is closer to the wheel hub and its strain gradient is largely dependent on the lateral force.

The detailed FEA results are shown in Figure 4. The stress difference between position $\mathrm{A}$ and position $\mathrm{B}$ are chosen for $\mathrm{Q}$ force identification as its steep gradient respect to the lateral load. Meanwhile, the two points have the identical stresses induced by the P force that means coupling effects could be eliminated. The $\mathrm{P}$ force identification is more difficult than the $\mathrm{Q}$ force. Firstly, the strain values and the influence zone on the wheel web induced by the $\mathrm{P}$ force are much smaller than the Q force, and the lower SNR is inevitable. Secondly, the effects of the varying contact positions must be considered.

The strain outputs at $\mathrm{A}$ and $\mathrm{B}$ under lateral and vertical loads are $\varepsilon_{Q}^{A}, \varepsilon_{Q}^{B}$, $\varepsilon_{P}^{A}$, and $\varepsilon_{P}^{B}$. The strain gradients are used for lateral loads identification as:

$$
\left\{\begin{array}{l}
\left(\varepsilon_{P}^{A}+\varepsilon_{Q}^{A}\right)-\left(\varepsilon_{P}^{B}+\varepsilon_{Q}^{B}\right)=\Delta \varepsilon_{Q} \\
\varepsilon_{P}^{A}=\varepsilon_{P}^{B}
\end{array}\right.
$$

$A$ and $B$ are chosen at the same horizonal positions of the strain curves under $\mathrm{P}$ forces where the gradient is only determined by $\mathrm{Q}$ force $\Delta \varepsilon_{Q}$ that means decoupling with $\mathrm{P}$ force.

Based on the above limitations, the position $\mathrm{C}, \mathrm{D}, \mathrm{E}$, and $\mathrm{F}$ are chosen for the $\mathrm{P}$ force identification. As illustrated in Figure 4, the stress distributions between $\mathrm{C}$ and $\mathrm{D}$ under varying the $\mathrm{P}$ loading positions are of the identical gradient and just be in different levels caused by the additional bending moments induced by the misaligned contact point. When the two strain gauges are placed at the two positions, the strain difference $\Delta \varepsilon_{Q}^{\prime}$ also contains bending component induced by the $\mathrm{Q}$ force which can be compensated by the strain difference between the position $\mathrm{E}$ and $\mathrm{F}$. Especially, as the concave slope feature of the $\mathrm{P}$ force, the points pair of $\mathrm{E}$ and $\mathrm{F}$ has the identical feature as the points pair of $\mathrm{A}$ and $\mathrm{B}$, that means the stress difference $-\Delta \varepsilon_{Q}^{\prime}$ is only sensitive to the $\mathrm{Q}$ force.

The strain outputs at $\mathrm{C}, \mathrm{D}, \mathrm{E}$ and $\mathrm{F}$ under lateral and vertical loads are $\varepsilon_{Q}^{C}$, $\varepsilon_{Q}^{C}, \varepsilon_{P}^{D}, \varepsilon_{P}^{D}, \varepsilon_{Q}^{E}, \varepsilon_{Q}^{E}, \varepsilon_{P}^{F}$, and $\varepsilon_{P}^{F}$. The synthetic strain outputs $\varepsilon^{C}, \varepsilon^{D}$, $\varepsilon^{E}$, and $\varepsilon^{F}$ are computed as:

$$
\left\{\begin{array}{l}
\left(\varepsilon_{P}^{E}+\varepsilon_{Q}^{E}\right)-\left(\varepsilon_{P}^{F}+\varepsilon_{Q}^{F}\right)=\varepsilon_{Q}^{E}-\varepsilon_{Q}^{F}=-\Delta \varepsilon_{Q}^{\prime} \\
\left(\varepsilon_{P}^{C}+\varepsilon_{Q}^{C}\right)-\left(\varepsilon_{P}^{D}+\varepsilon_{Q}^{D}\right)=\Delta \varepsilon_{P}+\Delta \varepsilon_{Q}^{\prime}
\end{array}\right.
$$

where $\Delta \varepsilon_{P}=\left(\varepsilon^{E}-\varepsilon^{F}\right)+\left(\varepsilon^{C}-\varepsilon^{D}\right)$ is decoupled with Q force and the effects of varying contact points are also eliminated. 

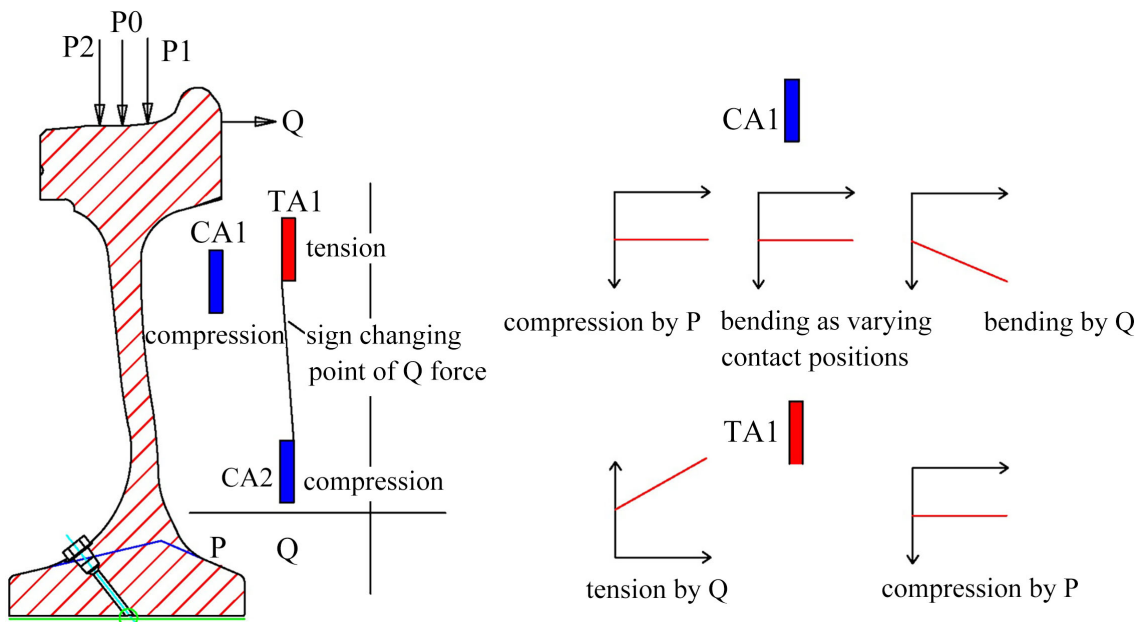

Figure 3. Sensitive areas on the inside wheel web.
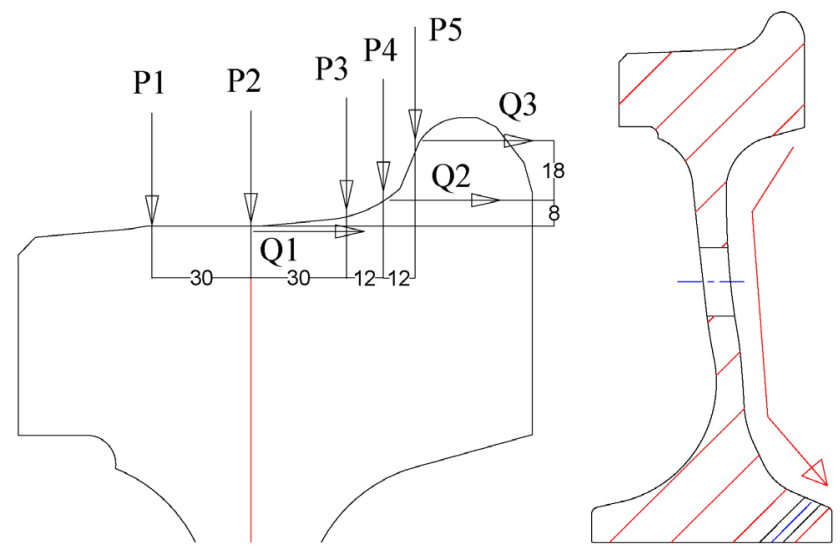

(a)

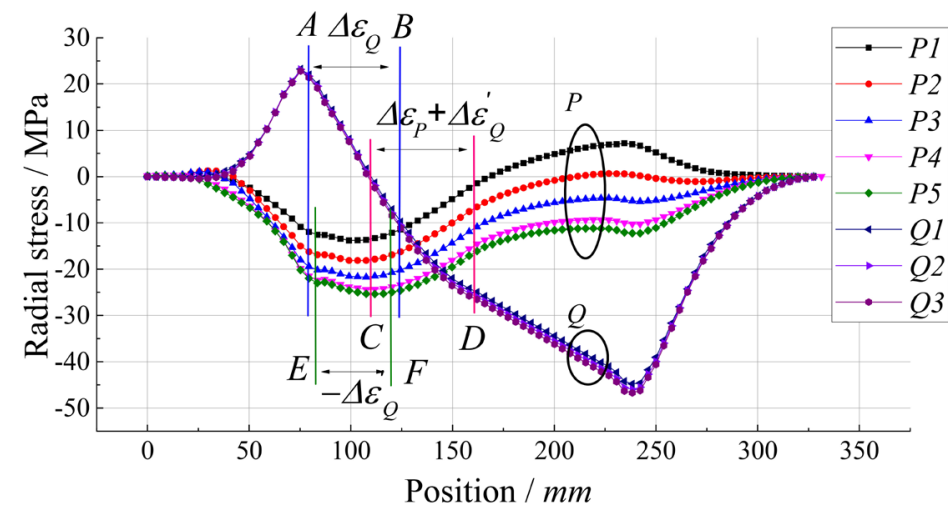

(b)

Figure 4. Stress distribution curves of the inside wheel web under the Q/P forces. (a) Loading points and result plotting path; (b) Radial stress distributions.

\subsection{Wireless Inductive Telemetry System for Signal Transferring}

To avoid drilling wiring holes on the axle, wireless signal transmission system must be adopted. The analog signals of the bridge outputs are conditioned and 
digitalized firstly and then transferred out by inductive ring. The inverse D/A transform, acquisition, and digital signal processes are further processed outside of the rotating wheelset. Otherwise, power supply of the telemetry system is also implemented by resonant inductive ring. The scheme of the commercial system from KMT is shown in Figure 5.

Auxiliary brackets for inductive ring and coil packaging blocks are special designed for motor and trailer bogies (CRH380BG high speed trains), as shown in Figure 6.

\section{Strain Gauges Layouts and Demodulating Technique}

The contact forces are rotating respect to the Wheatstone strain bridge when the vehicle is running. The rotation effects eliminating process using two bridges with 90 degrees delay is called signal demodulation. The principles of the common method SQ and ABS are shown in Figure 7.

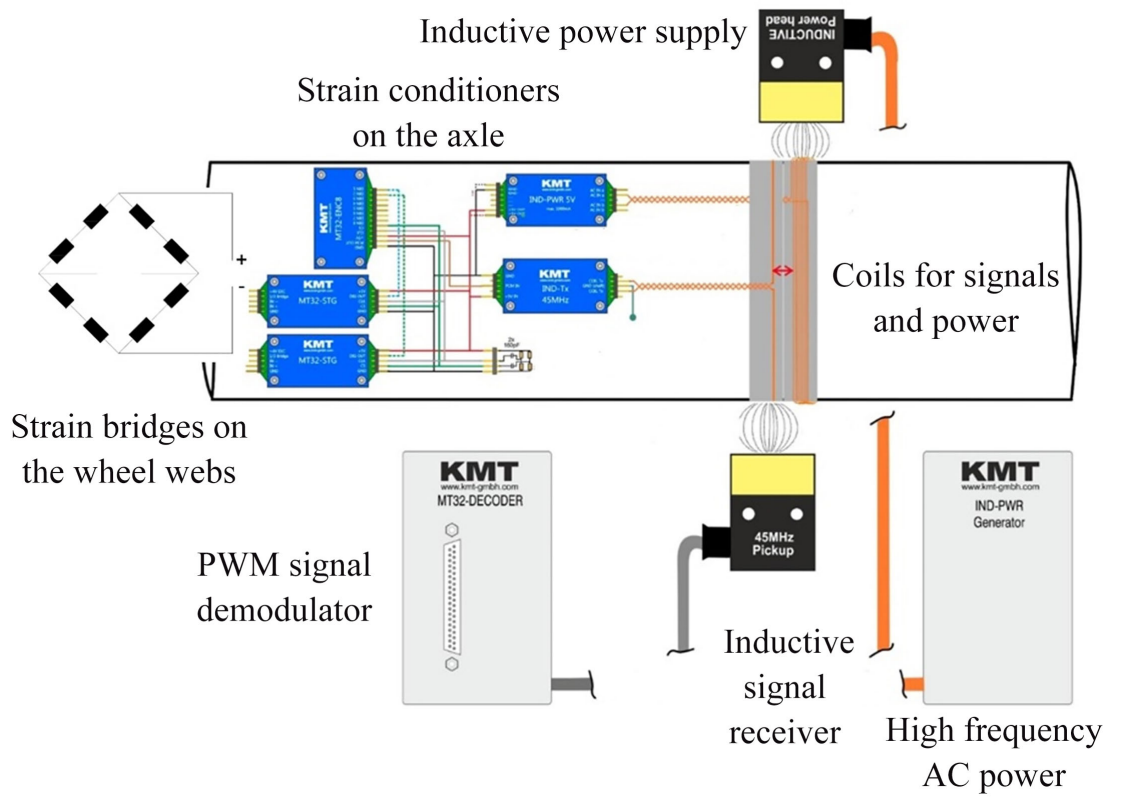

Figure 5. KMT telemetry system.

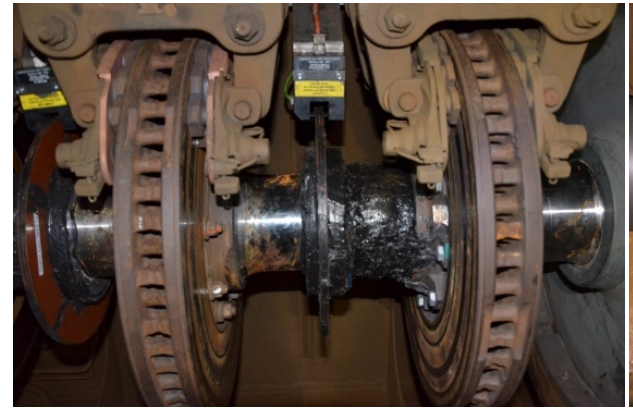

(a)

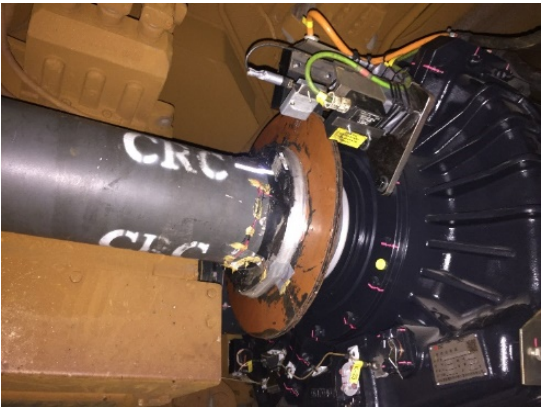

(b)

Figure 6. Auxiliary brackets for wireless inductive signal transferring system. (a) Trailer bogie; (b) Motor bogie. 

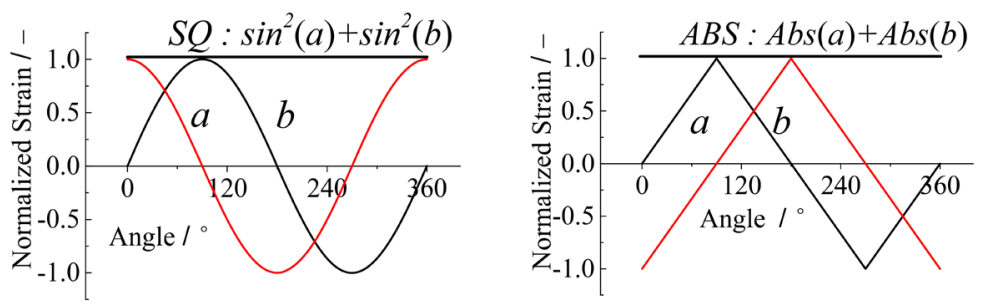

Figure 7. The demodulation principles of the two bridges.

The two-bridge demodulation method is only suitable under the condition that section angle of the stress influence zone is close to 180 degrees. The section angles of the stress influence zone under P and Q forces are shown in Figure 8 where section angle of the $P$ forces is smaller than 60 degrees that brings large high-order demodulating ripples when two-bridge scheme used. To reduce the amplitudes the ripples, three-bridge scheme for $\mathrm{P}$ force identification is proposed in the article.

\subsection{Lateral Contact Force Identification}

As mentioned above, the position A and B are chosen to calculate strain difference which is sensitive to the $\mathrm{Q}$ force only. Each branch of the full bridge consists of 2 gauges for minus operation. The full bridge is comprised of 2 opposite sectors of each has 2 branches with 60 degrees angle, as shown in Figure 9.

The layout of the two Wheatstone bridges with 90 degrees phase delay is shown in Figure 10.

The demodulated signals are calculated as follow:

$$
\varepsilon_{d}=\varepsilon_{p 0} \cdot \cos \theta-\varepsilon_{p 90} \cdot \sin \theta
$$

where $\varepsilon_{d}, \varepsilon_{0}$, and $\varepsilon_{90}$ are demodulated signals, output signals of the phase 0 and phase 90 bridges respetivly, and $\theta$ is the rotation angle of the wheelset through the tachometer.

The output wave the single bridge has difference with the sine wave that brings high order harmonics. There are tiny $4^{\text {th }}$ order ripples which can be eliminated by filtering in real-time or post data process.

\subsection{Vertical Contact Force Identification}

The output waveform of a single strain gauge at the loading condition only the $\mathrm{P}$ forces existing is much like a pulse with steep slope. As stress of the wheel web is less sensitive to the vertical loads, the sector angle of the influence zone is less than 60 degrees. The demodulated signals of the two-bridge scheme have large ripples with the four times frequency of the wheelset rotating, as shown in Figure 11. It will dramatically reduce the SNR level of the demodulated signals and cannot be eliminated by further filtering process.

To reduce the amplitude of the high order ripples, three-bridge scheme and demodulating algorithm were proposed. Three uniformly distributed with the section angle of 120 degrees were adopted as shown in Figure 12. For each bridge, the position $\mathrm{C}, \mathrm{D}, \mathrm{E}$, and $\mathrm{F}$ are chosen as a single branch for algebraic 
operations including stress difference calculations and compensation for coupling effects of the $\mathrm{Q}$ force.

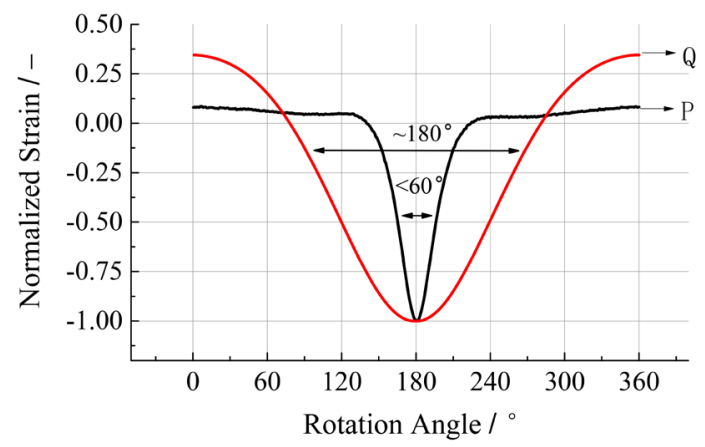

Figure 8. The stress influence zone section angles under $\mathrm{P}$ and $\mathrm{Q}$ forces.

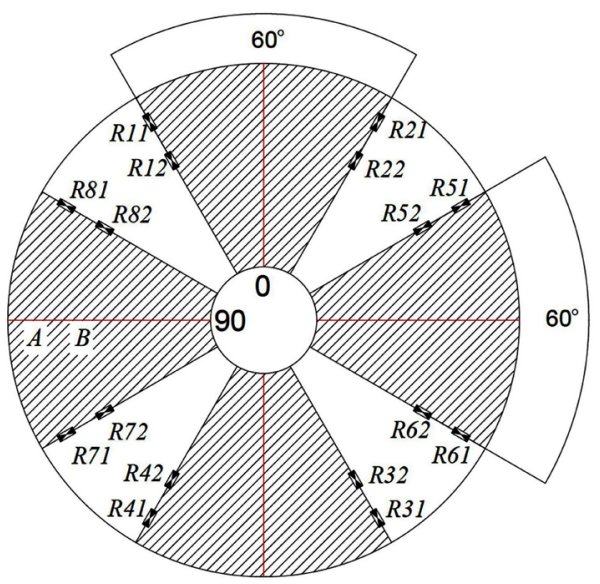

Figure 9. $Q$ force identification bridge layout.

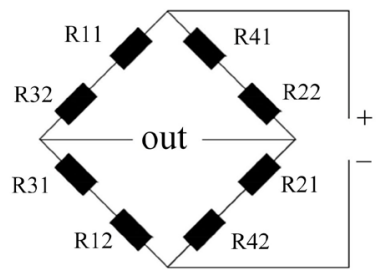

bridge phase 0

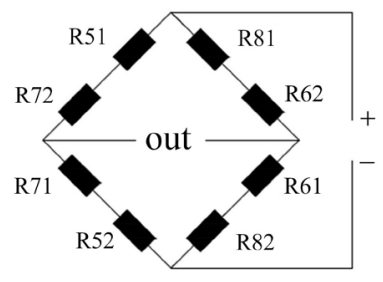

bridge phase 90

Figure 10. Double wheatstone bridges for $\mathrm{Q}$ force identification.

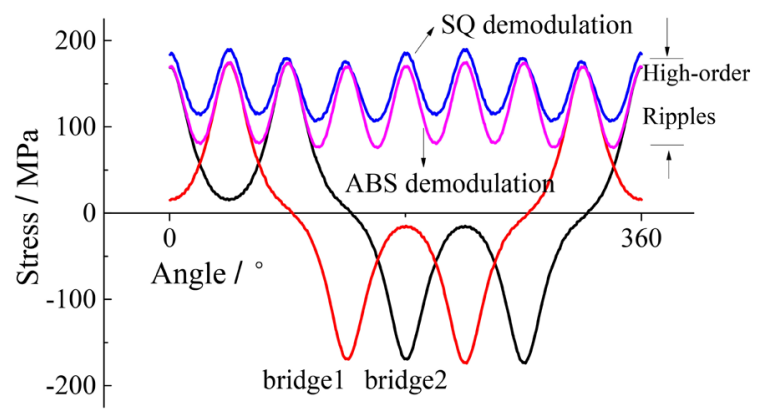

Figure 11. Dynamic stress difference (C, D) curve under P force. 


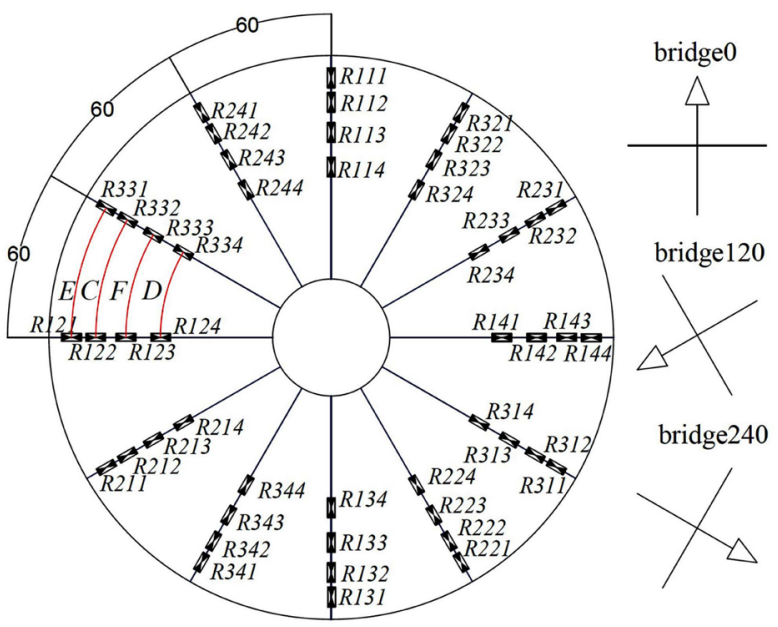

(a)

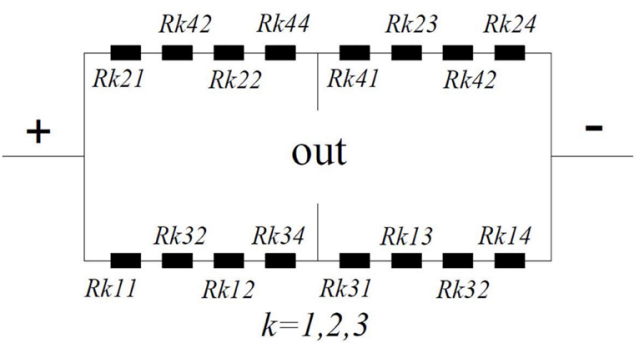

(b)

Figure 12. $\mathrm{P}$ force identification strain gauges layout. (a) $\mathrm{P}$ force identification bridge layout; (b) Three wheatstone bridges for P force identification.

According to the demodulation algorithm, the single bridge outputs is computed as:

$$
\begin{aligned}
\varepsilon_{k}= & \left\{\left(\varepsilon_{k 12}+\varepsilon_{k 13}-\varepsilon_{k 11 k}-\varepsilon_{k 14}\right)-\left(\varepsilon_{k 32}+\varepsilon_{k 33}-\varepsilon_{k 31}-\varepsilon_{k 34}\right)\right. \\
& \left.+\left(\varepsilon_{k 22}+\varepsilon_{k 23}-\varepsilon_{k 21}-\varepsilon_{k 24}\right)-\left(\varepsilon_{k 42}+\varepsilon_{k 43}-\varepsilon_{k 41}-\varepsilon_{k 44}\right)\right\}
\end{aligned}
$$

where $k=1,2,3$ is the bridge number, $\varepsilon_{k}$ is the brige $k$ strain output. The strain gauge number is $\varepsilon_{k m n}, m=1,2,3,4$ is bridge branch number, and $n=1,2,3,4$ is position number represents $\mathrm{E}, \mathrm{C}, \mathrm{F}$, and D.

The demotulation signals $\varepsilon_{d}$ are computed as:

$$
\varepsilon_{d}=\operatorname{Max}\left(\left|\varepsilon_{1}+\varepsilon_{2}\right|,\left|\varepsilon_{2}+\varepsilon_{3}\right|,\left|\varepsilon_{3}+\varepsilon_{1}\right|\right)
$$

\section{Test Rig Calibration}

The calibration tests were carried out by the test rig, as shown in Figure 13, that lateral and vertical loads can be applied individually through the cylinders. The wheelset can also rotate at a low speed for dynamic calibration.

The waveform outputs on the calibration rig are shown in Figure 14. The independent applied lateral and vertical force are $25 \mathrm{kN}$ and $85 \mathrm{kN}$ respectively. The fourth order ripples are introduced in the lateral force demodulation process of the amplitude ratio is about $2.5 \%$. The twelfth order ripples are introduced in the vertical force demodulation process of the amplitude ratio is about $7.5 \%$. 


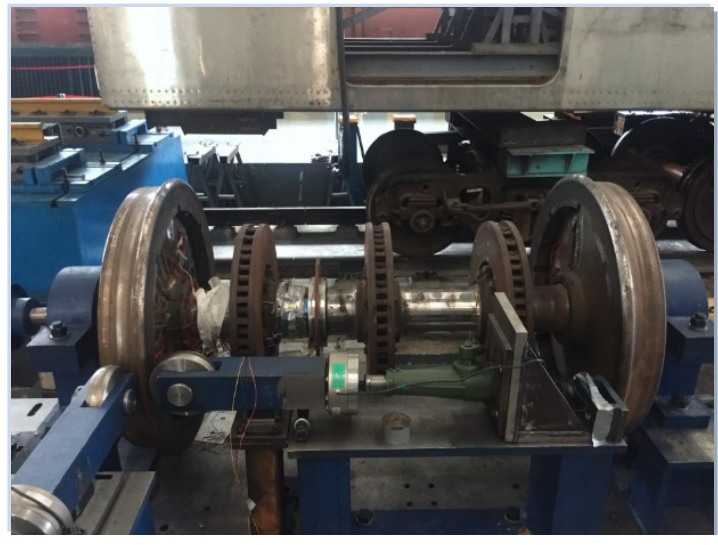

Figure 13. Calibration test rig.

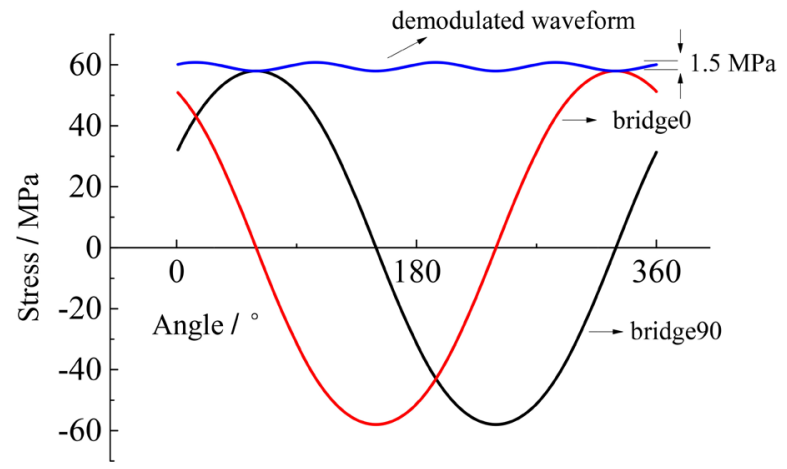

(a)

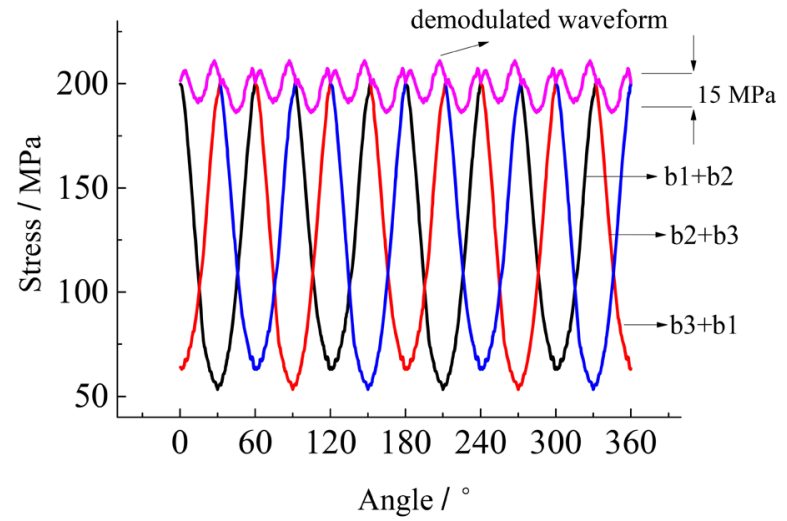

(b)

Figure 14. Bridges outputs and demodulated signals at the calibration test rig. (a) Q force $(25 \mathrm{kN})$; (b) P force $(85 \mathrm{kN})$.

\section{Conclusions}

The nondestructive instrumented wheelset could be implemented inside wheel web strain gauge placing scheme together with wireless signal transmission system.

1) The wireless telemetry system and strain gauge inside web placing scheme keep the structural integrity of wheelset that can be used in long-term contact force monitoring. 
2) Strain gradients are used for strain gauges poisoning to eliminate loads decoupling effects, and the effects of the varying contact points are also minimized.

3) The ripples amplitude ratios are $2.5 \%$ and $7.5 \%$ for lateral and vertical force identification, and the orders are 4 and 12 respecting to the wheelset rotating frequency. The high frequency demodulating disturbances could be eliminated by post filtering process.

\section{Conflicts of Interest}

The authors declare no conflicts of interest regarding the publication of this paper.

\section{References}

[1] International Union of Railways (2009) UIC 518, Testing and Approval of Railway Vehicles from the Point View of Their Dynamic Behaviour-Safety-Track Fatigue-Running Behaviour. 4th Edition, International Union of Railways, Paris.

[2] Papini, S., Pugi, L., Rindi, A., Meli, E., Papini, S. and Florence, U.O. (2013) An Integrated Approach for the Optimization of Wheel-Rail Contact Force Measurement Systems. Journal of Modern Transportation, 21, 95-102.

https://doi.org/10.1007/s40534-013-0013-z

[3] Gomez, E., Giménez, J.G. and Alonso, A. (2011) Method for the Reduction of Measurement Errors Associated to the Wheel Rotation in Railway Dynamometric Wheelsets. Mechanical Systems \& Signal Processing, 25, 3062-3077. https://doi.org/10.1016/j.ymssp.2011.05.006

[4] Gullers, P., Andersson, L. and Lundén, R. (2008) High-Frequency Vertical Wheel-Rail Contact Forces-Field Measurements and Influence of Track Irregularities. Wear, 265, 1472-1478. https://doi.org/10.1016/j.wear.2008.02.035

[5] Kanehara, H. and Fujioka, T. (2002) Measuring Rail/Wheel Contact Points of Running Railway Vehicles. Wear, 253, 275-283.

https://doi.org/10.1016/S0043-1648(02)00114-X 